\title{
Нуждаят ли се тийнейджърите от кохлеарна имплантация
}

\author{
С. Върбанова, Д. Попова \\ Катедра УНГ, Медицински университет - София
}

\begin{abstract}
The cochlear implant is a very expensive high profile medical therapy . Candidates for a cochlear implants are infants, children, as well as post - lingual deaf adults . One of the most important factors in auditory speech perception of cochlear implanted children Is the age of implantation. The goal of this study is to investigate teenager operated in Medical University - Sofia and determine the efficiency of cochlear implantation with regards to: Implant devise use, speech perception and speech intelligibility outcomes, document current academic occupational status of implanted prelingualy deaf children. The results suggest that CI provide everyday environmental sound perception and communicating skills and benefits in teenagers.
\end{abstract}

\section{Резюме}

Кохлеарната имплантация е скъпо, високотехнологично и специализирано лечение на глухотата. Кандидати за кохлеарна имплантация могат да бъдат деца и възрастни, отговарящи на определени критерии. Много важен фактор за развитието на говор след оперативната интервенция е възрастта, на която тя е извършена. Цел на това проучване е да се проследи групата от тийнейджъри, оперирани в Катедрата по УНГ болести на Медицински университет - София по отношение на употребата на кохлеарния имплант, възприемането и разбираемостта на говор, развитието на реч и говорни умения и образователния им статус. Резултатите показват, че кохлеарната имплантна система дава възможност за постоянна звукова перцепция от околната среда, подобряване на ежедневните комуникации и промяна на качеството на живот на оперираните в тази възраст.

\section{Увод}

Кохлеарната имплантация е добре известен и използван метод за хирургическо лечение на глухотата. Резултатите след оперативната интервенция варират в широки граници в зависимост от особеностите на индивида, причините за възникване на глухотата, възрастта, на която е извършена операцията, качеството и интензивността на следоперативната рехабилитация $(7,8,14)$. Възможността за възприемане на сигналите от околната среда и човешката реч поставят оперираните пред много предизвикателства каквито са развитие на говор, възможността за образоване и професионално развитие, промяна на навиците и ново качество на живот в света на звуците и на чуващите $(9,10,13)$. Кандидати за кохлеарна имплантация могат да бъдат индивиди с прелингвална и постлингвална глухота на различна възраст, отговарящи на необходимите условия и критерии. Особено препоръчителна е оперативна интервенция при незадоволителни или липсващи функционални резултати от предхождаща употреба на слухови апарати $(7,8,10)$. С последните технически достижения в кохлеарните импланти се получават все по-добри резултати и се разширяват критериите за имплантация, като подходящи за оперативно лечение вече се дискутират и деца с остатьчен слух за ниските честоти, наличие на прогресираща слухова загуба и глухота с голяма давност.

Така юношеската група по-често е обект на внимание по отношение на индикации за операция и следоперативните резултати $(1,2,3)$. Отчита се важната роля и на акустичната стимулация върху ЦНС за развитието на комуникативни възможности в различните периоди от съзряването и развитието на индивида (14). 
Важен фактор, определящ добрите следоперативни резултати (говорно и езиково развитие), особено при децата, е възрастта, на която те получават своя имплант $(1,11)$. Сложна е корелацията между имплантационната възраст и последващите резултати, която зависи от настоящата възраст, продължителността и опита от използването на импланта, придобитите слушателски умения със слухови апарати, възможността за отчитане по уста (leap reading) и участието и подкрепата на обкрьжението и семейството.

\section{Материал и методи}

Цел на това проучване бе да се проследят оперираните в Катедрата по УНГ болести на Медицинси университет - София, деца в тийнейджърска възраст и се отчете ефикасността и ползата от кохлеарната имплантация по отношение на:

- употребата на импланта

- възприемане и разбираемост на говор

- образователен статус

Проследени са 22 прелингвално оглушели деца, оперирани на възраст от 13 до 19 години в периода от 2004 до 2007 година, на които са имплантирани кохлеарни импланти на фирмите Cochlear и Medel. Групата се състои от 12 момчета и 10 момичета. Средната възраст, на която е извършена операцията, е 16 години. Проследената от нас група представлява $16 \%$ от всичките оперирани дотогава 124 пациенти. Продължителността на употребата на кохлеарното устройство варира от 6 месеца до 3 години. 10 от оперираните продължават да използват слухов апарат на неоперираното ухо.

Говорната разбираемост на групата бе тествана 1 година след началната стимулация с импланта т.нар. „включване”. Използвани бяха тестове от протокола TEEN EARS (Evaluation of Auditory Responses to Speech), който се състои от 7 теста и 1 въпросник и покриват различни степени на езикова компетентност, слушателски умения и психосоциални оценки.

Така се оценяват възможностите за чуване, възприемане и разбиране на човешката реч и звуци от обкръжението и ежедневието. Проследявахме и следоперативните резултати за възприемане на чисти тонове чрез FF audiometry.

\section{Резултати и обсъждане}

От проследената група 1 година след оперативнана интервенция:
- при 12 деца (около 55\%) реалностите са различни от очакванията, което е свързано с нехаресване и нередовност при употребата на кохлеарния имплант

- 3 (около 13\%) използват непостоянно КИ

- 7 от проследената група (около 32\%) ежедневно и целодневно си служат с кохлеарния имплант

По отношение на употребата и разбираемостта при телефонен разговор: 14 от проследените деца не могат да си служат и да провеждат разговори по телефон; 2 могат самостоятелно да провеждат и разбират без допълнителна помощ и устройства (самостоятелни ползватели) и 6 могат да провеждат телефонни разговори при определени ситуации и съответна помощ.

Отчитайки образователния статус на групата, установихме, че:

- 13 посещават масови училища

- 5 се обучават в специализирани училища

- в момента на проучването 3 са студенти

По отношение на доволството и ползата от употребата на кохлеарните импланти в групата тийнейджъри установихме, че някои от тях са особено доволни от кохлеарната имплантация, осигурила им възможност за комуникации по слухов път, без необходимостта за отчитане по уста (leap reading). Те благодарение на новите възможности, които дава КИ, и индивидуалните си качества развиват нови слушателски умения, което променя и качеството им на живот. Когато опитьт им с импланта нарасне, те могат в ежедневието да определят различен говор и звуци от обкръжението. Тези деца по-лесно комуникират в дома и извън него, по време на обучение и при различни други ситуации.

Отчетохме комплексно резултатите като:

А. Добри - при 12 от групата, с остатъчен слух в неоперираното ухо. Въпреки недобрия ефект от предхождащото операцията слухопротезиране те са добре рехабилитирани предоперативно и имат частично развита реч, с отчитане по уста (leap reading). При повечето от тези пациенти бе регистирано нарастващо с времето подобрение и задоволство от употребата на КИ.

Б. Незадоволителни резултати при 10 от децата с късно диагностицирана и оперирана вродена глухота, без слушателски навици и умения със слухови апарати и липса на предоперативна рехабилитация. 


\section{Дискусия}

Създаването на програми за рехабилитация и проследяване на резултатите от нея е много отговорна задача, при решаването на която да се има предвид и групата на тийнейджърите. Прилагането на оперативната интервенция кохлеарна имплантация в тази възраст им дава надежда и шанс за по-добро говорно и езиково развитие, отколкото с помощта на слухови апарати. Като определящи и свьрзани фактори се отчитат: употребата на слухови протези и съответното ниво на рехабилитация преди кохлеарната имплантация и продължителността на ползването на кохлеарната имплантационна система, времето от настьпването и диагностицирането на глухотата до операцията и продължителността на използването на импланта. Една година след началното усилване с импланта голяма част от тийнейджърите показват прогрес в разбирането и развитието на говор, при изпълнението на тестови задачи с различни цели.

Отчетените резултати демонстрират различна успеваемост при тийнейджърите поради различие в предоперативните говорни умения, рехабилитация и остатъчен слух в неоперираното

\section{Литература}

1. Yoshinaga-Itano C, Sedey D, Coulter D, Mehl A Languade of early - and later- identified children with hearing loss, Pediatrics, 1998; 102: 1161-71

2. Moeller MP Early identification and language development in children who are deaf and hard of hearing, Pediatrics, 2000; 106: 1-9

3. Kileny P, Zwolan T, Ashbangh C The influence of age of implantation on performance with a cochlear implant in children Oto Neurol. 2001; I, 22: $42-46$

4. Cochlear implantation in children yunger than 2 years old Am J Otol. , 1998; 19: 158-162

5. Zimmerman-Phillips S, Robbims AM, Osberger MJ Infant-Todler Meaningful Auditory Integration Scale Sylmar, Calif.: Advanced Bionics Corp; 2001

6. Fryant-Bertschy H, Tyler R, Kelsay D, Gantz B Cochlear implant use by prelingually deafened children: the influence of ade at implant and length of devise use J Speech Lang Hear Res., 1997; 40:183-199

7. Zwolan TA, Zimmerman-Philips S, Ashlaugh SJ, Kileny PR, Telian S Cochlear implantation in children with minimal open- set recognition skills Ear Hearq 1997; Jun; 18: 241-51

8. BeadleEA, McKinley DJ, NikolopoulosTP, Brough J, O’Donoghue, Archbold SM Long-term functional outcomes and academicoccupational status in implanted children after 10 to 14 years of cochlear implante use Otol Neurol. 2005 XI; 26 : 1152-60 ухо. Способността за възприемане и развитие на говор зависи и от качеството и нивото на предоперативната рехабилитация и възрастта в която е извършена оперативната интервенция $(7,11$, 13). Проследяването на развитието на слуховото възприятие е важно и позволява прогнозиране на говорните умения след кохлеарната имплантация, което може с успех да бъде извършвано с тестове от протокола TEEN EARS, като част от рехабилитационната програма на MEDEL.

\section{Изводи}

C тестовете TEEN EARS може да бъде оценявано и подпомагано възприемането на говор и речевите умения на пациентите в тийнейджърска възраст, по отношение на напасването на процесора и подпомагане на рехабилитацията им.

Получените от нас данни са доказателство за възможностите на оперираните юноши чрез използването на кохлеарната имплантационна система да добият самостоятелност и самочувствие при комуникацията си с обкръжаващата действителност и нейната звукова характеристика.
9. Liker M, Mildner V, Sindija B Acoustic analysis of speech of children with cochlear implants: a longitudinal study Clin Linguist Phon. 2007, I, 21: 1-11

10. Weeler A, Archold S, Gregory S, Skipp A Cochlear implants: the young people's perspective J Deaf Stud Deaf Educ. 2007;13: 313- 316

11. Connor CM, Craig HK, Raudenbuch SW, Heawner K, Zwolan Ta The age at which young deaf childrenreceive cochlear implants and their vocabulary and speech- production growth: is there an added value for early implantation ? Ear Hear. 2006, XII; 27; 628-44

12. Hassanzadeh S, Farhadi m, Daneshi A, Emamdjomeh $H$ The effects of age on auditory speech perception development in cochlear-implanted prelingually deaf children otolaryngol Head Neck Surg. 2002 ,V, 126: 524-7

13. Manrique M, Cervera-Paz FJ, Huarte A, Molina M. Prospective longterm auditory results of cochlear implantation in prelinguistically deafened children: the importance of early implantation Acta Otolaryngol Suppl. 2004, V, 552: 55-63

14. Waltzman SB, Roland JT, Cohen NL Delayed implantation in congenitally deaf children and adults Otol Neurotol. 2002, V, 23: 33340 